\title{
ESPETÁCULO, COMUNICAÇÃO E COMUNISMO EM GUY DEBORD
}

\author{
João Emiliano Fortaleza de Aquino* \\ emilianoaquino@bol.com.br
}

RESUMO O presente trabalho se orienta pela hipótese de que a reflexão sobre a linguagem e a crítica do fetichismo mercantil, de Guy Debord, são aspectos inseparáveis de um único e mesmo ponto de partida da crítica da "sociedade do espetáculo", centrado na crítica da linguagem e da formamercadoria. Debord se posiciona por uma transição, no que diz respeito ao horizonte da reflexão estética e social sobre a linguagem, do conceito de expressão ao de comunicação ou diálogo. Ele busca recolher e manter, ultrapassando-a, a natureza crítica da expressão não-comunicativa (e, por isso, refratária à "pseudocomunicação" da sociedade burguesa), tal como concebida e experienciada pela arte moderna e as vanguardas do início do século XX, formulando a perspectiva crítica social da comunicação direta.

Palavras-Chave Reificação; Linguagem; Expressão; Comunicação

ABSTRACT The present work is oriented by the hypothesis that Guy Debord's reflection on language and criticism of the commodity fetishism are inseparable aspects of a single and same point of departure of the criticism of "the society of the spectacle", centred on the criticism of language and commodity-form. Debord sets his view on a transition, concerning the horizon of the aesthetic and social reflection on language, from the concept of

* Professor de Filosofia da Universidade Estadual do Ceará (UECE) e da Universidade de Fortaleza (Unifor). O presente artigo baseia-se na tese de doutoramento Reificação e linguagem em André Breton e Guy Debord (PUC/SP, 2005). Artigo recebido em agosto de 2006 e aprovado em setembro de 2006.

KRITERION, Belo Horizonte, nº 115, Jun/2007, p. 167-182. 
expression to that of communication or dialogue. He seeks to compile, maintain and surpass the critical characteristic of uncommunicative expression (and, therefore, refractory to the pseudo communication of the bourgeois society), as it was conceived and experienced by modern art and the vanguards of the beginning of the $20^{\text {th }}$ century, formulating the social critical perspective of direct communication.

Keywords Reification; Language; Expression; Communication

A linguagem do homem absolutamente solitário é lírica, é monológica. Essa solidão não é simplesmente a embriaguez da alma aprisionada pelo destino e convertida em canto, mas também o tormento da criatura condenada ao isolamento e que anseia pela comunidade.

LUKÁCS, G. A Teoria do romance.

Publicado em 1967, o livro A sociedade do espetáculo, de Guy Debord (1931-1994), vem sendo, nos últimos anos, objeto de discussão em várias áreas disciplinares das ciências humanas, principalmente nos assim chamados estudos culturais. Ainda quando não é o próprio objeto em questão, seu principal conceito - o "espetáculo" - é incorporado a reflexões diversas, muitas vezes, contudo, com prejuízo de seu significado conceitual específico. Nas considerações no mais das vezes sociológicas desse conceito, o que se costuma perder é a pretensão central, anunciada em várias ocasiões por seu autor, a articular uma atualidade da crítica da economia política, incorporandolhe tanto a experiência e a tematização sobre a linguagem, internas às vanguardas e à arte moderna, quanto a retomada, em voga no início dos anos 1960, na França, de uma reflexão filosófica no marxismo, provocada naquele período pela publicação, em língua francesa, de Teoria do romance e História e consciência de classe, ambas de G. Lukács, e Marxismo e filosofia, de K. Korsch. ${ }^{1}$

1 "Fora-nos preciso retomar a crítica da economia política compreendendo de modo preciso e combatendo 'a sociedade do espetáculo'”, diz Debord (Notes pour servir à I'histoire de l'I. S. de 1969 a 1971, p. 95). A essa afirmação, devemos acrescentar esta outra, na qual Debord radica sua teoria nas discussões internas às vanguardas do segundo pós-guerra: "Quinze anos antes, em 1952, quatro ou cinco pessoas pouco recomendáveis de Paris decidiram pesquisar a ultrapassagem da arte. (...) A ultrapassagem da arte é a 'passagem ao noroeste' da geografia da vraie vie, que com freqüência fora tão procurada durante mais de um século, notadamente a partir da autodestruição da poesia moderna." (Préface à la quatrièmme édition italienne de La société du spectacle [1979], in: Commentaires sur la société du spectacle [1988], p. 130-131). 
Membro e fundador da Internacional Situacionista, Guy Debord recebe as publicações dessas obras - que foram centrais à discussão filosófica no âmbito da crítica teórica da sociedade, nos anos 1920-1930 do século passado - com base numa reivindicação da experiência das vanguardas artísticas do entreguerras, colocando-se, assim, a questão da atualidade do programa das vanguardas nas condições do capitalismo do segundo pós-guerra. O que resulta dessa reflexão é a proposição de uma teoria crítica do capitalismo tardio, na qual, com fundamento nos conceitos marxianos de alienação, fetichismo da mercadoria e reificação, a experiência social e estética da linguagem ocupa um lugar central. Com base nessa interpretação, pretendo apresentar neste artigo a articulação conceitual entre a crítica da forma-mercadoria e a crítica da linguagem reificada, sob a hipótese de que tal articulação constitui o centro da teoria crítica da "sociedade do espetáculo", concluindo por discutir como resulta dela uma perspectiva emancipatória, na qual a superação da reificação e a ultrapassagem da forma-arte são indissociáveis de uma concepção comunicativa da linguagem e da práxis sociais.

\section{Espetáculo, contemplação e perda da comunicação}

A base da teoria crítica proposta por Guy Debord é a constatação, no capitalismo contemporâneo, do domínio cotidiano, imediatamente fenomênico, da lógica abstrata da forma-mercadoria. Esta constatação é central ao conceito debordiano de "espetáculo", precisamente no que diz respeito às transformações da aparência do sistema capitalista. Com efeito, sob o conceito de espetáculo, momento da economia em que a mercadoria teria atingido a "ocupação total da vida cotidiana", o teórico situacionista busca unificar e explicar, segundo afirma, uma diversidade de "fenômenos aparentes", que são, eles mesmos, "as aparências desta aparência organizada socialmente" $(S d S, \S 10){ }^{2} \mathrm{O}$ que isto significa? Esta questão interroga sobre algo fundamental ao seu conceito de espetáculo. Para explicitá-la, é preciso, antes de tudo, considerar que o conceito de aparência nesta crítica teórica não remete, em primeiro momento, à aparência sensorial-visível, mas antes às categorias, de origem hegeliana, de aparência (Schein) e aparição (Erscheinung), nas quais Marx situa as trocas de equivalentes nos primeiros capítulos de $O$ capital, que tratam da circulação de mercadorias e dinheiro. Na exposição marxiana da crítica da economia política já se encontram articulados os conceitos de "esfera da circulação" e

2 DEBORD. La societé du spectacle. Doravante as referências desta obra serão feitas no corpo do próprio texto, com a indicação entre parênteses das iniciais da obra e do parágrafo em questão. 
de "aparência", justamente enquanto dizem respeito à experiência imediata, cotidiana, das trocas mercantis, condição da produção capitalista que é, contudo, posta pelo próprio capital e se constitui, portanto, na "forma de aparição do capital". ${ }^{3}$

Já nesta instância aparente da produção capitalista, instância constituída pelas trocas de mercadorias e dinheiro, enquanto equivalentes, na esfera da circulação, Marx vê manifestar-se uma objetividade fetichista que, nucleada pela lei do valor, escapa ao controle dos homens e se lhes impõe como "uma relação entre coisas". De modo expresso, Marx concebe o caráter fetichista da forma-mercadoria determinado não pela "natureza física" dos produtos ou pelas "relações materiais" presentes no intercâmbio prático entre os indivíduos durante sua produção, mas, exclusivamente, pela forma social desse mesmo intercâmbio, enquanto intercâmbio mercantil; portanto, aquele não diz respeito à aparência sensível, mas sim à "aparência objetiva das determinações sociais do trabalho". " É esta aparência objetiva do intercâmbio mercantil que se constitui numa objetividade fantasmagórica, pois se apresenta aos homens, em sua experiência prática, como uma relação natural, constitutiva das próprias coisas, embora seja uma determinação da forma histórica de suas relações sociais. Contudo, trata-se de uma aparência necessária, pois constitutiva da lei do valor que per se aparece, já na esfera da circulação, com a objetividade e com a necessidade de uma lei natural. Para Marx, portanto, a natureza fantasmagórica e fetichista da forma-mercadoria, não sendo determinada por sua forma sensorial, não se constitui, em conseqüência, numa ilusão unilateral da consciência, mas sim numa ilusão que poderíamos dizer objetiva, na medida em que a experiência cotidiana das trocas monetário-mercantis, enquanto trocas de equivalentes, "vela, em vez de revelar, o caráter social dos trabalhos privados e, portanto, as relações sociais entre os produtores privados". ${ }^{5}$ É neste sentido que a consciência "dos produtores privados apenas reflete [espelha, spiegelt $]$ (...) aquelas formas que aparecem na circulação prática, na troca de produtos (...)". ${ }^{6}$ Em outras palavras, a consciência cotidiana espelha aí "mais

3 MARX. O capital, p. 125, t. I/1. Enquanto aparência do capital, a circulação de mercadorias e dinheiro não é o falso, ao qual se opõe uma instância verdadeira (neste caso, a produção do capital), como suporia uma concepção metafísica simplista. Para Marx, é "impossível que o produtor de mercadorias, fora da esfera de circulação, sem entrar em contato com outros possuidores de mercadorias, valorize valor e, daí, transforme dinheiro em capital. (...) Capital não pode, portanto, originar-se da circulação e, tampouco, pode não se originar da circulação. Deve, ao mesmo tempo, originar-se e não se originar dela" (p. 138). É justamente neste sentido que a esfera da circulação é a forma de aparição do capital, instância aparente que o compõe necessariamente.

4 MARX. O capital, p. 71, t. I/1.

5 Ibidem, p. 73.

6 Ibidem, p. 72. 
nada que determinada relação social entre os próprios homens que para eles aqui assume a forma fantasmagórica de uma relação entre coisas". ${ }^{7}$

É esta aparência social fetichista, constituída pela circulação de mercadorias e dinheiro, que, segundo Debord, estende sua lógica ao conjunto das atividades e relações cotidianas no capitalismo espetacular, produzindo e organizando as "aparências", os "fenômenos aparentes", estes sim sensorialmente visíveis, imediatamente presentes na experiência social dos indivíduos. A aparência objetiva do intercâmbio mercantil, da qual Marx afirma, categoricamente, a autonomia e a independência em face da "natureza física" e das "relações materiais" da produção de valores de uso, torna-se agora fisicamente aparente, sensivelmente visível. Torna-se uma aparência socialmente organizada que se manifesta, no capitalismo espetacular, em fenômenos sensorialmente aparentes, graças à extensão das relações mercantis à totalidade da vida cotidiana. Precisamente assim, a autonomia, frente aos indivíduos, da aparência das trocas fetichistas de valores passa a constituir soberanamente, submetido à sua lógica abstrata, um conjunto de fenômenos aparentes visíveis, que, desse modo, se tornam, eles próprios, também autônomos frente aos indivíduos.

N'O capital, Marx se refere à mercadoria como uma "coisa fisicamente metafísica". Em sua análise do capitalismo contemporâneo, Debord observa um movimento especulativo dessa abstração constitutiva do valor econômico em direção ao sensível, movimento pelo qual, contudo, este não tem restituída a sua autonomia material, mas, sim, bem ao contrário, é completamente subsumido à abstração do valor. Em sua teoria crítica do capitalismo espetacular, Debord concebe justamente que o valor de troca, chegado a um tal nível de autonomia, pelo superacúmulo de capital e, conjuntamente, pela extensão de sua lógica ao conjunto do espaço-tempo vivido, pode apresentar-se na imediatidade da totalidade dos valores de uso, e de tal modo que a sua lógica abstrata não apenas se torna imediatamente visível, mas é também a única coisa que se faz ver. Desse modo, as experiências cotidianas dos indivíduos, situadas na esfera aparente do sistema constituída pela circulação monetário-mercantil, tornam-se, elas próprias, enquanto experiências subsumidas à lógica da troca de equivalentes, fenômenos aparentes da produção capitalista.

Essa autonomização dos fenômenos aparentes da abstração do valor econômico é nomeada por Debord como "mundo da imagem autonomizado" $(S d S, \S 2)$. Contudo, não se trata - como julga criticamente Mario Perniola - de "uma atitude iconoclasta que considera com suspeição as formas sensíveis". ${ }^{8} \mathrm{O}$ 
espetáculo não seria, diz Debord, "um conjunto de imagens, mas uma relação social entre pessoas mediada por imagens" ( $S d S, \S 4)$. No uso do conceito de imagem, Debord não faz primeiramente uma referência estrita à visão sensível, mas antes a um "modo de produção", do qual o espetáculo seria, não um "suplemento", ou uma "decoração acrescentada", mas, justamente enquanto "forma de aparição do capital" (Marx), "a afirmação onipresente da escolha já feita na produção e sua consumação corolária” ( $S d S, \S$ 6). O que Debord tem em vista sob o conceito de imagem são as relações sociais fetichistas, fundadas na autonomização do valor e estendidas à totalidade do uso social do tempo, do espaço, para além do trabalho assalariado, mas essencialmente obedecendo à sua lógica disciplinar e contemplativa. As imagens e representações que, no espetáculo, substituem o diretamente vivido são, antes de tudo, uma forma de relação social nas quais os indivíduos, que nela se relacionam, se posicionam efetivamente como espectadores contemplativos em e de suas próprias atividades e relações genéricas.

Se Debord pode conceber o espetáculo como constituído na produção, como modo de produção, é fundamentalmente porque julga que, "com a separação generalizada do trabalhador e de seu produto, se perde todo ponto de vista unitário da atividade realizada, toda comunicação direta entre os produtores"; em conseqüência, "a atividade e a comunicação se tornam o atributo exclusivo da direção do sistema" ( $S d S$, § 26). Em outras palavras, o conceito de espetáculo, não dizendo respeito ao "simples olhar", diz do "que escapa à atividade dos homens, à reconsideração e à correção de sua obra. É o contrário do diálogo" ( $S d S, \S 18)$. Se se tem em vista estas duas últimas passagens citadas, compreende-se que, sob o conceito de espetáculo, Debord busca essencialmente articular duas fundamentais dimensões constitutivas da aparência social, num momento em que a forma-mercadoria se estende ao conjunto do vivido: a expropriação da atividade autônoma, inseparável da expropriação da linguagem comunicativa. ${ }^{9}$

O que primeiramente, pois, é central ao conceito de espetáculo é que, conforme ele, a extensão horizontal das trocas de equivalentes traz à "superfície" da vida social (a aparência do metabolismo do capital, no sentido

9 Neste sentido, a reflexão dele sobre aparência social no capitalismo mais desenvolvido não considera apenas a visibilidade do produto mercantil, sua "estética", sua "aparência". Esta é somente uma determinação - cf. $\S 15$ de A sociedade do espetáculo - deste movimento mais amplo de dominação do vivido pela reificação fetichista do valor. Tampouco ele considera centralmente a tendência - realmente existente - da produção cultural tardocapitalista a se voltar para produtos sensorialmente "visíveis", centrados na "imagem" e na "visão" ocular, como salienta, de modo simpático, mas unilateral, F. Jameson (A cultura do dinheiro, ensaios sobre a globalização, especialmente p. 87 et seq. e 114 et seq.). 
de Marx) a contemplação que é essencial ao trabalho assalariado e que, de todo modo, está na base desta mesma universalização da forma-mercadoria dos produtos do trabalho. Ter em conta esta relação entre o trabalho assalariado e o espetáculo é importante, pois responde à frequiente crítica de que esta última categoria estaria limitada à esfera da circulação de mercadorias e não concerniria à produção do capital. ${ }^{10}$ Deve-se lembrar que, para Marx, "só a partir desse instante [em que a força de trabalho assume, para o próprio trabalhador, a forma de uma mercadoria] se universaliza a forma mercadoria dos produtos do trabalho". ${ }^{11}$ Esta universalização não está dissociada, portanto, daquilo mesmo que caracteriza a produção capitalista enquanto produção de mais-valor. Em sua concepção crítica do espetáculo, Debord tem em conta que a extensão das trocas mercantis funda uma transformação - ou, se se quiser, um ajuste - na aparência social, com a emergência de um conjunto totalitário de fenômenos que produzem e exigem, já na imediatidade do vivido, a passividade contemplativa própria ao trabalho assalariado. Sua consideração sobre a aparência social não se restringe, portanto, à esfera das trocas de equivalentes, mas busca pensar as experiências sociais imediatas dos indivíduos numa situação histórica na qual o intercâmbio mercantil se mostra, na totalidade extensiva dos seus mais diversos fenômenos, tão hierárquico e contemplativo quanto o é a própria produção mercantil fundada no salariato. A instância das trocas iguais, que simultaneamente compõe e oculta a produção do capital, passa a manifestar de modo aparente a contemplação que, no trabalho assalariado industrial, é essencial à própria produção do valor.

A "contemplação" - categoria que, para L. Feuerbach e o jovem Marx, é inerente à inversão especulativa sujeito-predicado - é tomada por Debord, nisto seguindo o Lukács de História e consciência de classe, como uma forma de relação social própria a este momento extensivo da relação mercantil. $\mathrm{O}$ espetáculo é, assim, uma inversão especulativa entre o sensível e o suprasensível, que ganha forma histórica concreta no domínio do valor sobre o valor de uso, domínio este cuja base última é a inversão entre o produtor e seu produto operada pelo trabalho alienado. Para Debord, o capitalismo mais desenvolvido apresenta, de modo imediato, fenomênico e aparente, a lógica da abstração supra-sensível do valor econômico, impondo uma inversão entre sensível e supra-sensível que, desde sempre, fora imanente ao fetichismo da forma-mercadoria. Não se tem aí, portanto, uma denúncia do sensível em nome

10 Sobre esta crítica, cf., entre outros: DAUVÉ. Kritik der Situationistischen Internationale; BLANC, L'Internazionale situazionista e il suo tempo.

11 MARX. O capital, p. 141, n. 41. 
de uma realidade verdadeira supra-sensível, mas, rigorosamente ao contrário, é a denúncia da dominação da abstração do valor econômico sobre o sensível; é a compreensão crítica de que, nas condições do capitalismo avançado, a lógica supra-sensível do valor tornou-se imediata, imajada, transformando o próprio sensível em algo do mesmo modo abstrato (tal como ocorre na quantificação do tempo, no lazer mercantil, na banalização do espaço, no consumo de mercadorias...). É como imagem que se impõe para ser vista e contemplada, que o automovimento do capital se constitui em experiência de passividade contemplativa na imediatidade da totalidade do vivido.

Uma segunda dimensão inseparável desta primeira é a que diz respeito às relações comunicativas entre os indivíduos. Não se trata, neste caso, de separar, muito menos de opor, como o faz A. Jappe, à "importância atribuída [por Debord] à "comunicação", uma suposta "grande novidade efetiva da [sua] teoria [que] decorre (...) de sua referência ao papel fundamental da troca e do princípio de equivalência na sociedade contemporânea". ${ }^{12}$ Ora, se a alienação da atividade produtiva se revela, quando as relações mercantis se universalizam na totalidade das experiências e relações cotidianas, como essencialmente o "contrário do diálogo", é precisamente porque, segundo Debord, a expropriação da atividade produtiva no capitalismo pressupõe a - e resulta necessariamente na - perda da comunicação direta entre os produtores. A expropriação da atividade autônoma no trabalho e a expropriação da linguagem comunicativa são duas determinações que se refletem reciprocamente. G. Agamben ressalta esta determinação recíproca ao considerar como fundamental à teoria crítica do espetáculo que, nela, "a análise marxiana vai integrada no sentido de que o capitalismo (...) não era voltado só à expropriação da atividade produtiva, mas também, sobretudo, à alienação da própria linguagem, da própria natureza lingüística ou comunicativa do homem". ${ }^{13}$ Debord apresenta, portanto, uma crítica teórica do capitalismo desenvolvido na qual se encontram articuladas, de modo inseparável, a passividade mercantil e a instrumentação reificada da linguagem. Para ele, o capitalismo contemporâneo se caracteriza essencialmente por uma mesma e única expropriação do diálogo e da atividade

12 JAPPE. Guy Debord, p. 189. Em História e consciência de classe, obra à qual Jappe relaciona com razão $A$ sociedade do espetáculo, já está presente este nexo entre a contemplação e a expropriação da comunicação, nexo ao qual, contudo, Jappe não deu em sua análise a devida importância.

13 AGAMBEN. Violenza e speranza nell'ultimo spettacolo, p. 14-15. Nesta mesma perspectiva de análise, P. Virno acentua que, sob a categoria de espetáculo, o que está em questão é um modo de produção, no qual "a comunicação humana tornou-se mercadoria". Daí que, segundo Virno, a interpenetração entre trabalho assalariado e expropriação da comunicação humana expresse, no pensamento de Debord, a exigência de que a crítica do capitalismo deva comportar a crítica da concepção instrumental da linguagem, de modo que a "abolição do trabalho assalariado" se constitui também, de modo essencial, em "liberdade da linguagem" (VIRNO. Cultura e produzione sul palcoscenico, p. 19-26). 
autônoma, condição e consequiência necessárias da universalização de relações sociais presididas pela lei do valor.

\section{Poesia moderna, movimento operário e comunismo}

Compreendida nesta dupla valência, a natureza visível e imediata da dominância da forma-valor no capitalismo contemporâneo é uma determinação central não apenas ao conceito de espetáculo, mas também, por isto mesmo, à afirmação prospectiva imanente à crítica que Debord elabora. Como aproximadamente propõe a psicanálise em relação ao sonho e às imagens oníricas, toda a questão é traduzir em desejo consciente, através da linguagem e da práxis comunicativas, as possibilidades de uma outra vida que se encontram ocultadas/apresentadas nas "imagens" constitutivas do capitalismo espetacular. Metafisicamente, essa posição essencialmente comunicativa da crítica social ampara-se no conceito de linguagem comum. ${ }^{14}$ Historicamente, baseia-se tanto nas experiências anti-hierárquicas do movimento operário, notadamente nos Conselhos Operários do primeiro quarto do século XX, quanto nas experiências expressivas da arte moderna, contemporâneas daquelas mesmas experiências operárias revolucionárias. Neste âmbito de reflexão, Debord pensa o desenvolvimento artístico moderno como componente do processo histórico de dissolução da "antiga linguagem comum", dissolução levada a cabo, antes de tudo, pelo próprio desenvolvimento do capitalismo em sua natureza destrutiva das relações sociais pré-modernas. Ao pensar esta experiência artística como parte integrante da experiência social da linguagem, cujo elemento destrutivo foi assumido criticamente pela escrita e pela figuração plástico-pictórica modernas, Debord articula um sentido social prospectivo para a experiência histórica da arte moderna, sentido este que, para ele, é inseparável da superação revolucionária das presentes condições de existência.

Nesta juntura entre a experiência histórica da linguagem e a experiência artística moderna, Debord formula uma teoria tanto da constituição histórica quanto da crise da arte autônoma. Resumidamente, ele assim a concebe: a

14 Não é aqui o lugar para desenvolver este problema, mas se pode dizer, sucintamente, que a categoria da linguagem comum em Debord assume até mesmo uma feição metafísica, no mesmo sentido em que o são as de gleiche Sprache, "linguagem igual, comum", na Teoria do romance (Lukács), e de Erfahrung, "experiência coletiva e comunicável", n'O narrador (Benjamin). Em todos esses casos, trata-se de indicar uma passagem, uma transição e uma não-fixidez da experiência histórica presente. Esta relação entre as categorias de linguagem comum em Lukács, Benjamin e Debord, eu a desenvolvi melhor em Reificação e linguagem em Guy Debord (Fortaleza: EdUECE, 2006). 
experiência estética que, antes, se punha como "linguagem comum da inação social", inseparável do "universo religioso" nas sociedades pré-modernas, se constitui, através da dissolução da antiga linguagem comum, em "arte independente no sentido moderno", quando "sua afirmação independente é o começo de sua dissolução" ( $S d S, \S 186)$. Esta formulação aponta para um movimento de constituição histórica do estatuto moderno da arte, enquanto experiência estética apartada, separada, de um todo social interligado; em suma, como experiência distinta daquela antiga pertença imediata dos fenômenos estéticos a uma totalidade comunitária fechada. Para ele, a arte independente se constitui historicamente de sua emergência do antigo universo mítico-religioso, como saída de uma linguagem comum tradicional; é precisamente este o processo que, ao apartá-la do universo integrado da comunidade pré-capitalista, no qual um sentido transmitido está conservado, a constitui enquanto arte independente, residindo, nisto mesmo, o começo de sua dissolução como arte, simplesmente. $\mathrm{O}$ que propriamente a constitui enquanto arte moderna autônoma é, portanto, a sua assunção da crise - pondose a si mesma como o lugar da "autodestruição crítica" - da experiência e da linguagem comuns da tradição. Liberada para sua autonomia, pela destruição de seu antigo ethos histórico, a arte moderna se constitui enquanto tal ao se colocar como uma experiência na qual aquela destruição é assumida, segundo Debord, "criticamente".

Encontrar-se-ia, assim, na arte moderna, uma "autodestruição crítica da antiga linguagem comum" (grifos meus). Todo o seu movimento é o da tematização e da experimentação conscientes e significativas desta destruição da linguagem, movimento pelo qual sua própria existência se faz inseparável desta experiência histórico-social mais geral. A importância deste processo está em que, para Debord, "a libertação da vida cotidiana... passa pelo deperecimento das formas alienadas da comunicação". ${ }^{15}$ Este deperecimento foi conscientemente tematizado e efetivado pela arte moderna. Ao compreendêla nesta articulação histórica com a própria linguagem social, e tendo em vista, criticamente, a natureza anticomunicativa do capitalismo contemporâneo, Debord busca justamente propor um sentido histórico prospectivo para essa experiência, sentido no qual a feição crítica da destruição da antiga linguagem comum na e pela arte moderna é conservada: "O fato de que a linguagem da comunicação se perdeu", diz ele, "eis o que exprime positivamente o movimento de decomposição moderna de toda arte, sua aniquilação formal. O 
que este movimento exprime negativamente é o fato de que uma linguagem comum deve ser reencontrada" ( $S d S, \S 187)$.

Segundo esse entendimento, toda a arte moderna foi a manifestação conscientemente positiva da destruição da antiga linguagem comum, que ela afirmou e requereu sob a forma da estética expressiva. Igualmente assim ela se fez arte independente, retirando-se do antigo universo religioso, destruindo-se criticamente a si mesma como pertencente àquele universo, constituindo, desse modo, sua própria independência formal num processo inseparável da destruição social da antiga linguagem comum. Contudo, na medida em que faz de si mesma o lugar de uma destruição consciente da linguagem tradicional, a arte moderna inscreve um sentido prospectivo a este seu fazer-se, sentido este que assinala em negativo a busca de uma outra, não alienada, "linguagem comum". Se a destruição da antiga linguagem comum é componente da natureza destrutiva da sociedade capitalista, a sua assunção pela arte moderna numa estética expressiva é também uma posição crítica em face desta forma de sociabilidade, caracterizada pela pseudocomunicação. Ora, é justamente em sua posição crítica diante da comunicação cotidiana reificada da sociedade capitalista, inseparável da perspectiva comunicativa que nela se inscreve negativamente, que, segundo Debord, a arte moderna se encontra historicamente com as experiências comunicativas, conselhistas e assembleárias do movimento operário revolucionário. O desenvolvimento da arte moderna, em sua natureza expressiva, aponta em negativo a busca de realização de uma outra linguagem comunicativa que, em suas experiências horizontais e anti-hierárquicas, o movimento operário ensaiou em positivo num diálogo prático de negação da linguagem unilateral e exterior do Estado. ${ }^{16}$

Para melhor determinação dessa perspectiva comunicativa que Debord elabora em sua crítica teórica do capitalismo mais desenvolvido, se pode ensaiar uma distinção entre a sua posição e a formulada por Theodor Adorno. Para este autor, a oposição ético-estética entre "expressão" (Ausdruck) e "comunicação" (Kommunikation) tem precisamente o significado de uma posição negativa diante da "comunicação" reificada na sociedade de mercado,

16 É na natureza negativa, crítica, da destruição da linguagem, em e pela arte moderna, tanto quanto nas experiências comunicativas e anti-hierárquicas do movimento operário que Debord fundamenta a perspectiva histórica da linguagem comunicativa. Não se trata, pois, da linguagem comum das comunidades pré-capitalistas, como interpreta M. Löwy, para quem em Debord se encontraria um "protesto contra a civilização capitalista/industrial em nome de valores do passado" - Consumé par le feu (Le romantisme de Guy Debord), Lignes, Paris, Harzan-Lignes, n. 31, 1997, p. 163. Tampouco Debord parte, em sua crítica da linguagem reificada, do pressuposto positivo de uma "essência humana", como supõe A. Jappe, para quem a posição do situacionista quanto à reificação "supõe, evidentemente (sic), a existência de uma 'essência humana' que possa servir de parâmetro para determinar o que é 'são' e o que é 'alienado'” (Guy Debord, p. 51). 
da qual a expressão se constitui numa denúncia (essencialmente integrante do conteúdo socialmente crítico da arte moderna). ${ }^{17}$ Adorno estrutura toda a sua perspectiva estética - que ocupa importante lugar em sua crítica social do capitalismo tardio - na oposição entre Ausdruck e Kommunikation, mesmo numa situação em que ele próprio reconhece a crise da categoria estética da expressão nas experiências neutralizadas das "neovanguardas". Contudo, ele a reafirma porque permanece teoricamente comprometido com a "forma autônoma da arte", tal como teria sido, segundo sua análise, experienciada pela arte moderna no entre-guerras, buscando aí acentuar o caráter crítico da autonomia da arte em face da heteronomia dominante no capitalismo tardio. Ao contrário, Debord busca superar essa oposição, não optando, contudo, pela comunicação alienada contra a expressão, mas concebendo a possibilidade de uma "comunicação direta". Tal como concebida por Debord, a comunicação direta tem o sentido exatamente contrário ao da Kommunikation criticada por Adorno, por ele próprio e, segundo a análise de ambos, pela arte moderna expressiva. Porém, Debord pretende ir além de uma afirmação da expressão contra a comunicação reificada das atuais relações sociais. Não desprezando ou contornando, mas precisamente tomando como fundamento o sentido crítico dessa oposição, Debord busca ultrapassá-la dialeticamente, numa perspectiva comunicativa.

Por isso mesmo, sua concepção comunicativa é diametralmente oposta à crítica que J. Habermas apresenta diante da perspectiva expressiva de Adorno. Antes de tudo, não se trata, para Debord, de distinguir fenomenologicamente mundo da vida e mundo sistêmico, como o faz Habermas em sua teoria do agir comunicativo, mas, ao contrário, de indicar num procedimento dialético que a lógica reificada da forma-mercadoria e do trabalho assalariado organiza a inteira vida cotidiana. Em conseqüência, o chamado mundo da vida, categoria com a qual Habermas pensa a vida cotidiana, é de pronto determinado pelo mundo sistêmico das relações econômicas fetichistas. Não se trata, assim, para Debord, de tomar a comunicação cotidiana, como existente na presente sociedade alienada, como base de uma perspectiva social comunicativa, tal como pretende Habermas, que se refere a uma "racionalização da comunicação cotidiana, ligada às estruturas intersubjetivas do mundo da vida, para a qual a linguagem representa o meio genuíno e insubstituível de entendimento". ${ }^{18}$ Para Debord, a presente comunicação cotidiana, em todos os seus níveis de

17 ADORNO. Teoria estética, especialmente, p. 56; Ästhetische Theorie, p. 68.

18 HABERMAS. Teoría de la acción comunicativa, especialmente o tópico IV "De Lukács a Adorno: La racionalización como coisificación", p. 437. 
"racionalização", é constituída pela mediação autônoma das relações mercantis, logo, é uma "pseudocomunicação". Numa posição solidária à de Adorno, R. Duarte diz, justamente contra a posição de Habermas, que "se nenhum dos participantes de uma ação mediada pela linguagem está imbuído dessa negatividade tão essencial à filosofia, a 'comunicação' entre eles raramente ultrapassará o nível fático, no qual operam as instâncias ideológicas do mundo administrado". Nesse sentido, uma " “ação comunicativa' só se efetiva de fato a partir do momento em que ela está apta a incorporar plenamente uma negatividade radical com relação ao atual estado de coisas". ${ }^{19}$ É precisamente por satisfazer essa exigência, tomando-a como pressuposto, que a perspectiva comunicativa de Debord pode ser entendida como uma ultrapassagem dialética da posição adorniana, incorporando-a. Ao invés de desviar-se dela, abandonando-a em favor de uma perspectiva comunicativa acrítica, como é o caso de Habermas, Debord incorpora a negatividade existente na oposição entre a expressão e a comunicação reificada, tal como esta oposição foi constituída pela arte moderna e tematizada por Adorno.

Assim, em face da natureza essencialmente anticomunicativa do capitalismo contemporâneo, no qual a expressão estética já não mais manteria inteira a potencialidade negativa que possuíra no entre-guerras, Debord se posiciona por uma perspectiva comunicativa como posição crítica e como projeto social de superação da reificação. Também nesse aspecto impõe-se uma radical diferença de sua concepção com a teoria do "agir comunicativo", que Habermas iria articular alguns anos depois: não se trata, para Debord, de buscar uma fundamentação transcendental para a "práxis comunicativa". ${ }^{20}$ Trata-se, isto sim, de pensá-la fundada única e exclusivamente na práxis negativa em face do sistema único de alienações do mercado e do Estado, negatividade esta que a expressão poética moderna e as revoluções proletárias derrotadas, notadamente em suas experiências conselhistas e assembleárias, isto é, antihierárquicas, teriam indicado. É somente enquanto reivindica esta negatividade imanente à experiência da arte moderna e própria à tradição revolucionária do movimento operário que, para Debord, o programa da superação da arte,

19 DUARTE. Expressão como fundamentação, p. 63.

20 É possível até mesmo uma demarcação terminológica entre o "agir comunicativo" (kommunikatives Handeln), concebido por Habermas, e a práxis comunicativa, concebida por Debord, demarcação que traduz justamente as diferenças conceituais acima observadas. Filologicamente, chamo a atenção para a filiação dialético-crítica da categoria da práxis, presente em Debord, que se distingue da categoria mais neutra do agir (Handeln), presente em Habermas; em seguida, para a escolha por Habermas dos termos alemães Kommunikation, kommunikativ e derivados - objetos de crítica na tradição dialética alemã, mormente em Adorno - para determinar o "agir" que ele tem em vista, em clara distinção com a Mitteilung, termo quase metafísico que, nesta mesma tradição dialético-crítica, expressa um sentido forte, autêntico, de comunicação. 
buscada pelas vanguardas do início do século, significa nas condições do capitalismo espetacular o programa da passagem da estética expressiva à práxis social comunicativa. Nessa perspectiva, a revolução proletária far-se-á herdeira da arte moderna, ao realizar positivamente o programa comunicativo que, em negativo, lhe é imanente; em contrapartida, a arte moderna realizarse-á, superando-se enquanto arte separada, com a transformação da inteira vida cotidiana em vida criativa, desalienada e histórica.

Desse modo, como crítica social, esta perspectiva comunicativa significa a afirmação de um sentido forte de comunicação que não se identifica, mas ao contrário se opõe, buscando superá-la, à experiência social reificada do "intercâmbio", da "comunicação". É esta concepção - inseparável da reivindicação, por Debord, da "tradição insurrecional" (Benjamin) da poesia moderna - que essencialmente o afasta das diversas correntes marxistas, pois, para ele, a anticomunicação, fundada na forma-mercadoria, constitui também as diversas outras formas de hierarquias sociais, a representação política, as "teorias" separadas da práxis (ideologias), a concepção do partido dito "revolucionário", o sindicalismo e o Estado. Em suma, trata-se de uma perspectiva comunicativa que carrega, com radicalidade, um sentido outro de comunicação, que reapresenta o projeto marxiano de uma sociedade sem classes e cuja condição histórica primeira é a superação do domínio fetichista do valor. Marx se referia ao comunismo, n'O capital, como constituído de "relações transparentes e racionais [dos homens] entre si e com a natureza". ${ }^{21}$ É essa mesma perspectiva que se reapresenta com Debord na formulação de uma "transparência imediata de uma certa comunicação, do reconhecimento recíproco, do acordo". ${ }^{22}$ Esta reivindicação debordiana da "transparência" se refere estritamente às possibilidades sociais do diálogo e da comunicação nas decisões executórias acerca da vida comum dos homens numa sociedade liberada do domínio fetichista das formas-valor. Sem esta última liberação, nenhum diálogo verdadeiro e potente é possível à escala social; mas também nenhuma verdadeira superação da economia autônoma é possível sem a práxis comunicativa. É esta juntura entre práxis comunicativa e comunismo - por sua vez constituída pela juntura entre revolução proletária e poesia moderna - que fundamentalmente caracteriza a crítica social de Debord. Para ele, tratase de opor à sociedade reificada, desde as lutas sociais cotidianas, a busca por 
"uma comunicação direta (...) que possa, assim, transformar o mundo segundo seu desejo". ${ }^{23}$

\section{Referências bibliográficas}

ADORNO, T. Teoria estética. Trad. Artur Morão. Lisboa/São Paulo: Martins Fontes, 1988.

. Ästhetische Theorie. Frankfurt am Maim: Shurkamp Verlag, 1970.

AGAMBEN, G. et al. I situazionisti. Roma: Manifestolibri, 1991.

AGAMBEN, G. Violenza e speranza nell'ultimo spettacolo. In: AGAMBEN, G. et al. I situazionisti. Roma: Manifestolibri, 1991.

AQUINO, J. E. F. Reificação e linguagem em Guy Debord. Fortaleza: EdUECE, 2006.

BLANC, D. L'Internazionale situazionista e il suo tempo. Milano: Colibri, 1998.

DAUVÉ, G. Kritik der Situationistischen Internationale. In: OHRT, R. (Hg.). Das grosse Spiel. Die Situationisten zwischen Politik und Kunst. Hamburg: Nautilus, 1999.

DEBORD, G. Notes pour servir à l'histoire de l'I. S. de 1969 a 1971. In: La

Véritable Scission dans l'Internationale [1972]. Paris: Fayard, 1998.

DEBORD, G. La societé du spectacle. Paris: Gallimard, 1992. (Col. Folio). - A sociedade do espetáculo. Prefácio à $4^{a}$ edição italiana de $A$ sociedade do

espetáculo. Comentários sobre a sociedade do espetáculo. Trad. Estela dos Santos Abreu. Rio de Janeiro: Contraponto, 1997. . Commentaires sur la société du spectacle. Paris: Gallimard, 1992. . Euvres cinématographiques complètes 1952-1978. Paris: Gallimard, 1994.

DEBORD, G.; SANGUINETTI, G. La Véritable Scission dans l'Internationale. Paris: Fayard, 1998.

DUARTE, R. Expressão como fundamentação. Kriterion, Belo Horizonte, Departamento de Filosofia FAFICH/UFMG, n. 91, jan.-jul./1995.

HABERMAS, J. Teoría de la acción comunicativa, I. Trad. M. J. Redondo. Madrid: Taurus, 1987.

INTERNACIONAL SITUACIONISTA. Internationale Situationniste 1958-1969. Texte intégral des 12 numéros de la révue. Édition augmentée. Paris: Librairie Arthème Fayard, 1997.

JAMESON, F. A cultura do dinheiro, ensaios sobre a globalização. Trad. M. E. Cevasco e M. C. P. Soares. Petrópolis: Vozes, 2001.

JAPPE, A. Guy Debord. Trad. I. Poleti. Petrópolis: Vozes, 1999.

LÖWY, M. Consumé par le feu (Le romantisme de Guy Debord). Lignes, Paris, Harzan-Lignes, n. 31, 1997. 
LUKÁCS, G. História e consciência de classe. Trad. Telma Costa. Porto: Publicações Escorpião, 1974.

MARX, K. O capital. Trad. R. Barbosa e F. R. Kothe. São Paulo: Nova Cultural, 1985. t. I/1.

. Das Kapital. In: Karl Marx - Friedrich Engels Werke, B. 23. Berlin, DDR: Dietz Verlag, 1962.

PERNIOLA, M. A estética do século XX. Tr. port. A. Cardoso. Lisboa: Editorial Estampa, 1998.

VIRNO, P. Cultura e produzione sul palcoscenico. In: AGAMBEN, G. et al. I situazionisti. Roma: Manifestolibri, 1991. 